\title{
Biosynthesis of 2-O-a-D-glucopyranosyl-L-Ascorbic Acid from Maltose by Cyclodextrin Glucanotransferase from Bacillus sp. SK 13.002
}

\author{
Ahmed Eibaid, Mohanad Bashari, Ming Miao, Abubakr Musa, Tao Zhang, Bo Jiang* \\ State Key Laboratory of Food Science and Technology, Synergetic Innovation Center of Food Safety and Nutrition, Jiangnan \\ University, Wuxi, China \\ *Corresponding author: bjiang@jiangnan.edu.cn
}

Received April 11, 2014; Revised May 12, 2014; Accepted May 14, 2014

\begin{abstract}
In this work 2-O- $\alpha$-D-glucopyranosyl-L-ascorbic acid (AA-2G) was synthesized by Cyclodextrin glucanotransferase (CGTase) from Bacillus sp. SK 13.002 with L-ascorbic acid (AA) as an acceptor and maltose as a glycosyl donor. AA-2G production was analyzed by HPLC and was confirmed by LC/MS results. The reaction parameters, such as $\mathrm{pH}$ (4.0-9.0), temperature $\left(25-50^{\circ} \mathrm{C}\right)$, time (0-30 h), substrate ratios and enzyme concentration were optimized. The results showed that the optimum condition was $\mathrm{pH} 8.0$ at $37^{\circ} \mathrm{C}$ for $24 \mathrm{~h}, 1: 1$ maltose to AA substrates mass ratio, and $200 \mathrm{U} / \mathrm{mL}$ of CGTase. Under these conditions, the production of AA-2G was $5.5 \mathrm{~g} / \mathrm{L}$, this result indicate that CGTase from Bacillus sp. SK 13.002 can effectively uses maltose as a glycosyl donor to produce AA-2G in high yield.
\end{abstract}

Keywords: Cyclodextrin glucanotransferase, 2-0- $\alpha$-D-glucopyransyl-L-ascorbic acid, maltose

Cite This Article: Ahmed Eibaid, Mohanad Bashari, Ming Miao, Abubakr Musa, Tao Zhang, and Bo Jiang, "Biosynthesis of 2-O- $\alpha$-D-glucopyranosyl-L-Ascorbic Acid from Maltose by Cyclodextrin Glucanotransferase from Bacillus sp. SK 13.002.” Journal of Food and Nutrition Research, vol. 2, no. 4 (2014): 193-197. doi: 10.12691/jfnr-2-4-10.

\section{Introduction}

Vitamin $\mathrm{C}$ is the common name for L-ascorbic acid (AA), a six-carbon sugar derivative of L-threo-hex-2enono-1,4-lactone [1]. The nutritional importance of vitamin $C$ as an essential water-soluble vitamin is well established. It has long been known that a nutritional deficiency in vitamin $C$ causes scurvy, a disease characterized by bleeding gums, impaired wound healing, anemia, fatigue, and depression, which, without proper care, can eventually be fatal [2]. AA can also act as a cofactor for the hydroxylation of proline and lysine residues in collagen, a major protein component of the body [3]. However, vitamin $\mathrm{C}$ is extremely unstable in aqueous solution, especially in the presence of heat, light, $\mathrm{Cu} 2+$, and ascorbate oxidase, which reduces its biological activity and limits its applications [4,5].

Different AA derivatives have been chemically synthesized as attempts to improve the stability of AA, such as AA-2-O-phosphate (AA-2P) [6], AA-2-O-sulfate (AA-2S) [7], and AA-2-methyl ether (AA-2M) [8]. Some vitamin glycosides are present in nature [9], but AA glycosides are only available as chemicals or via enzymatic synthesis [10]. The molecule 2-O- $\alpha-\mathrm{D}-$ glucopyranosyl-L-ascorbic acid (AA-2G) was enzymatically synthesized by Yamamoto et al. [11] via transglycosylation using $\alpha$-glucosidase. AA-2G is stable against enhanced oxidative degradation by heat, $\mathrm{Cu}^{2+}$ ion, or ascorbate oxidase, and it was found to have no reducing activity [4]. AA-2G is extremely stable and is considered to be superior to other chemically synthesized AA derivatives in terms of reaction specificity and efficiency in large-scale production [4]. AA-2G is available as AA well [12]; therefore it has found wide application in cosmetics, medicines and foods [5].

Although AA-2G can be produced by different enzymes [11,13,14], but studies have shown that cyclodextrin glucanotransferase (CGTase) is the most preferable either mostly in free [15], immobilized [16], recombinant [17], or in mutant state [18]. CGTase transfer glucose unit to $C_{2}$ in $A A$ via transglycosylation from glycosyl donor, different substrates were used as glycosyl donor except glucose $[15,17]$. Cyclodextrins $(\alpha$ and $\beta$ ) are best substrates for CGTase for the production of AA-2G, but they found limitation for industrial applications due to the cost of $\alpha$-cyclodextrin and low solubility of $\beta$ cyclodextrin. Maltose was used as substrate, it represents best choice due to it is low cost and high solubility compared to cyclodextrins, but the production of AA-2G was weak due to low specificity $[15,17]$. CGTase specificity for synthesis AA-2G using maltose was improved by site-saturation engineering of lysine 47 and the yield was $1.12 \mathrm{~g} / \mathrm{L}$ [19]. This yield is too low compared to $13 \mathrm{~g} / \mathrm{L}$ of $\mathrm{AA}-2 \mathrm{G}$ that produced by recombinant CGTase using $\beta$-cyclodextrin as a glycosyl donor [17]. Therefore finding of CGTase with high 
specificity for synthesis AA-2G from maltose will assist to narrow the wide gab with $\beta$-cyclodextrin. In this research work, maltose was used as a glycosyl donor for production of AA-2G by CGTase from Bacillus sp. SK 13.002 .

\section{Materials and Methods}

\subsection{Materials}

AA-2G standard was from Hayashibara Biochemical Laboratories (Okayama, Japan), AA and glucoamylase were from Sigma. All other analytical grade chemicals were purchased from Sinopharm Chemical Reagent Co., Ltd (Shanghai, China).

\subsection{Methods}

\subsubsection{Bacterial Strain and Enzyme Production}

Bacillus sp. SK 13.002 originally was isolated from soil sample in our laboratory. The 16S rRNA gene sequences for this strain have been deposited in the National Center for Biotechnology Information NCBI GenBank database under accession number GU570959 [20]. After cultivation for $96 \mathrm{~h}$, cells were removed by centrifugation at 10,000 rpm and $4^{\circ} \mathrm{C}$ for $15 \mathrm{~min}$. The supernatant was used as crude enzyme solution, which was concentrated using Millipore ultra-filtration system (Millipore Company, USA) with a molecular cut-off point of $10 \mathrm{kDa}$. The concentrated enzyme solution was precipitated with $70 \%$ saturated ammonium sulfate at $4^{\circ} \mathrm{C}$. The mixture was centrifuged at $10,000 \mathrm{rpm}, 4^{\circ} \mathrm{C}$ for $15 \mathrm{~min}$ and the pellets were dissolved in $20 \mathrm{mM}$ Tris- $\mathrm{HCl}$ buffer ( $\mathrm{pH} \mathrm{8.0)}$ and dialysed against the same buffer overnight at $4^{\circ} \mathrm{C}$. The solution obtained after dialysis was freeze-dried and the resulting CGTase powder was used in carrying out all experiments.

\subsubsection{Enzymatic Production of AA-2G}

The reaction mixture consisted of $\mathrm{AA}$, maltose as a glycosyl donor, and CGTase in $0.1 \mathrm{M}$ acetate buffer $(\mathrm{pH}$ 6.0). The reaction mixture was incubated at $40^{\circ} \mathrm{C}$ for $24 \mathrm{~h}$ in the dark in a shaking water bath. Glucoamylase (10 $\mathrm{U} / \mathrm{mL}$ ) was added to the mixture and incubated at $65^{\circ} \mathrm{C}$ and $\mathrm{pH} 5.5$ for $6 \mathrm{~h}$ to hydrolyze the AA-2oligosaccharides (AA-2G $)$ to AA-2G and glucose.

\subsubsection{HPLC analysis of AA-2G}

Agilent Technologies 1200 Series (USA) connected with ODS-HYPERSIL column (4x250 mm) was used in this study. The assay conditions were a detection wavelength of $240 \mathrm{~nm}$, mobile phase of $0.1 \mathrm{M}$ $\mathrm{KH}_{2} \mathrm{PO}_{4} / \mathrm{H}_{3} \mathrm{PO}_{4}(\mathrm{pH} 2.0$ ), and a flow rate of $0.5 \mathrm{~mL} / \mathrm{min}$. The reaction mixture was centrifuged at $13000 \mathrm{rpm}$ for 15 min and the supernatant was filtered through a $0.45 \mu \mathrm{m}$ membrane before injection. The AA-2G concentration was calculated on the basis of peak area from standard curve with coefficient of correlation (r2) equal 0.9993. All experiments were conducted at least twice.

\subsubsection{LC/MS/MS Analysis of AA-2G}

LC/MS/MS (Waters Acquity UPLC and PDA; Waters Maldi Synapt Q-T of MS) was operated in negative ion detection mode; ultra pure synthetic air was used as a nebulisation desolvation gas (flow rate $=500 \mathrm{l} / \mathrm{h}$ ) and MS fragment ions were obtained with $15 \mathrm{eV}$ collision energy. The eluent consisted of gradient, A 100\% methanol and B 0.1 formic acid using BEH C18 column $(2.1 \times 50 \mathrm{~mm} 1.7$ $\mu \mathrm{m})$ at $0.3 \mathrm{~m} / \mathrm{l}$ flow rate, $245 \mathrm{~nm}$, and at $45^{\circ} \mathrm{C}$.

\section{Results and Discussion}

\subsection{Enzymatic Production of AA-2G}

The reaction mixture consists of, AA, maltose, and CGTase from Bacillus sp. SK13.002 in 0.1 M acetate buffer. HPLC profile of the reaction mixture (Figure $1 \mathrm{~A}$ ) showed production of AA-2G (peak 2) at $7.5 \mathrm{~min}$ followed by AA-2-oligosaccharides; $A A-2 G_{2}$ and AA-2 $G_{3}$ at peaks 3 and 4 respectively. AA-2G production was 0.68 $\mathrm{g} / \mathrm{L}$, after addition of glucoamylase $(10 \mathrm{U} / \mathrm{mL})$, AA-2oligosaccharides were hydrolyzed and AA-2G production was increased to $1.06 \mathrm{~g} / \mathrm{L}$ (Figure $1 \mathrm{~B}$ ). However, glucoamylase in addition to hydrolyze AA-2oligosaccharides, it will also hydrolyze AA-2G; previously glucoamylase concentration was optimized [17]. Formation of AA-2-oligosaccharides by CGTase from Bacillus sp. SK 13.002 when maltose was used as a glycosyl donor is consistent with the result of CGTase from Paenibacillus sp [15]. On the other hand result of CGTase from Paenibacillus macerans showed that AA-2oligosaccharides were not produced when maltose was used as a glycosyl donor [19].

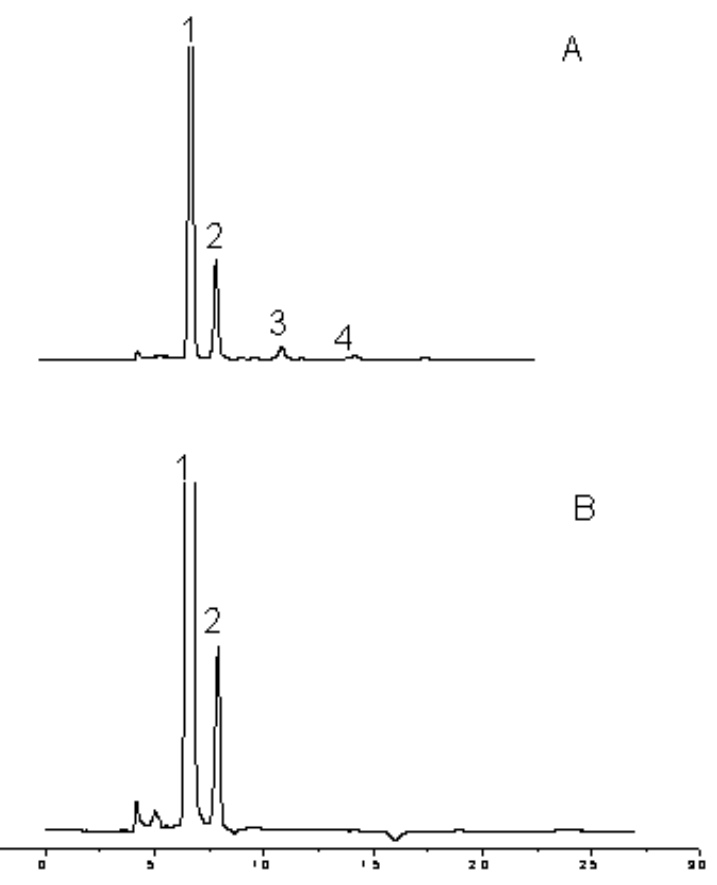

Figure 1. HPLC profiles: (A) Reaction mixture product of CGTase with AA and maltose at $40^{\circ} \mathrm{C}$ for $24 \mathrm{~h}$. (B) Reaction mixture after addition of glucoamylase to reaction mixture. 1: AA, 2: AA-2G, 3: AA-2G, and 4: AA- $2 \mathrm{G}_{3}$

\subsection{Confirmation of AA-2G Production by LC-MS/MS}

LC-MS/MS results (Figure 2) showed that mass spectrum of sample AA-2G (Standard) revealed a protonated molecule [M-H]- at $337 \mathrm{~m} / \mathrm{z}$, and this 
molecular ion produced ions at 277, 174, and $114 \mathrm{~m} / \mathrm{z}$. The reaction mixture showed a protonated molecule [M$\mathrm{H}]-$ at $337 \mathrm{~m} / \mathrm{z}$, and this molecular ion produced ions at 277, 174, and $114 \mathrm{~m} / \mathrm{z}$, this result confirmed the production of AA-2G in the reaction of AA with maltose catalyzed by CGTase from Bacillus sp. SK13.002. The reaction mixture also showed other two peaks (data not shown) with protonated molecule [M-H]- at 499 and 661 $\mathrm{m} / \mathrm{z}$, these peaks related to $A A-2 G_{2}$, and $A A-2 G_{3}$ respectively. LC-MS/MS results are summarized in Table 1.
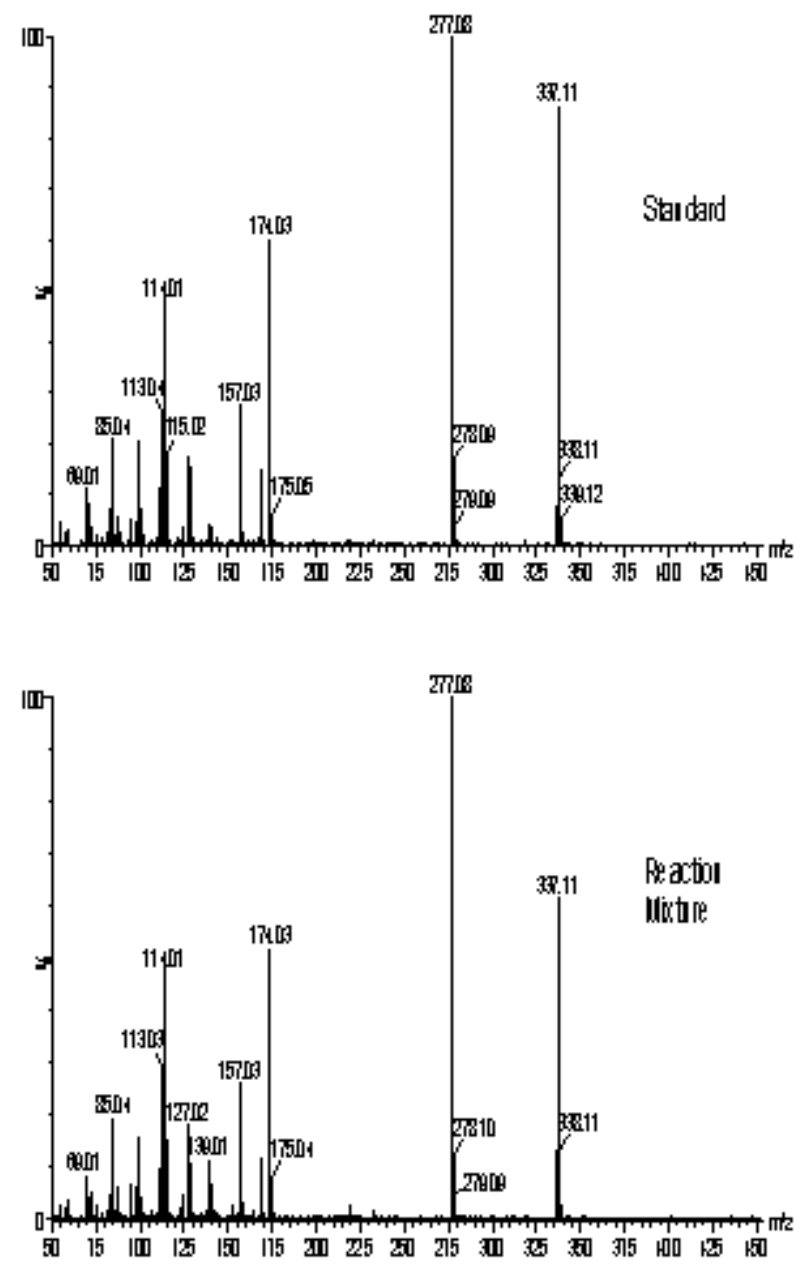

Figure 2. LC-MS/MS profile for standard (AA-2G) and reaction Mixture (AA-2G) product of AA, maltose and CGTase

Table 1. LC-MS/MS Feature of the ascorbic acid transglycosylated products

\begin{tabular}{ccc}
\hline Product & Retention time $(\min )$ & {$[\mathrm{M}-\mathrm{H}]^{-}$} \\
\hline $\mathrm{AA}-2 \mathrm{G}$ & 1.892 & 337.1 \\
$\mathrm{AA}-2 \mathrm{G}_{2}$ & 2.556 & 499.2 \\
$\mathrm{AA}-2 \mathrm{G}_{3}$ & 3.308 & 661.2 \\
\hline
\end{tabular}

\subsection{Optimization of AA-2G Production}

\subsubsection{Influence of Reaction $\mathrm{pH}$ and Temperature}

The influence of $\mathrm{pH}$ was studied using different buffers, sodium acetate (4.0-6.0), sodium phosphate (6.0-8.0), and Tris- $\mathrm{HCl}(8.5$ - 9.0). AA-2G production with acetate buffer showed gradual increase but, with phosphate buffer showed semi exponential increase and reached the maximum at $\mathrm{pH} 8.0$ (Figure $3 \mathrm{~A}$ ). With Tris-HCl buffer AA-2G production rapidly was decreased. AA-2G optimally was produced by CGTases with $\mathrm{pH}$ from 5.5-
6.5. On the other hand, AA-2G was produced at $\mathrm{pH} 7.5$ by Sucrose phosphorylase [21], but this is first time AA-2G is produced at $\mathrm{pH}$ 8.0. One of two isozymes of CGTase from Bacillus sp. SK 13.002 has an optimum hydrolysis activity in $\mathrm{pH} 8.0$ [20]. This result is consistent with result of $\alpha$-CGTase from recombinant Escherichia coli, which was showed transglycosylation maximum $\mathrm{pH}$ for AA-2G production same as optimum cyclization activity at $\mathrm{pH} 5.5$ [17].

The influence of temperature was studied with $\mathrm{pH} 8.0$ at $25-50^{\circ} \mathrm{C}$ (Figure $3 \mathrm{~B}$ ), the optimum temperature for AA-2G production was at $37^{\circ} \mathrm{C}$, other CGTase showed same maximum temperature [17] while other CGTases showed optimum transglycosylation temperature for AA$2 \mathrm{G}$ production around $37^{\circ} \mathrm{C}[18,19,22]$. On the other hand, CGTase from Bacillus stearothermophilus showed a maximum transglycosylation temperature for AA-2G production at $70^{\circ} \mathrm{C}[23]$.
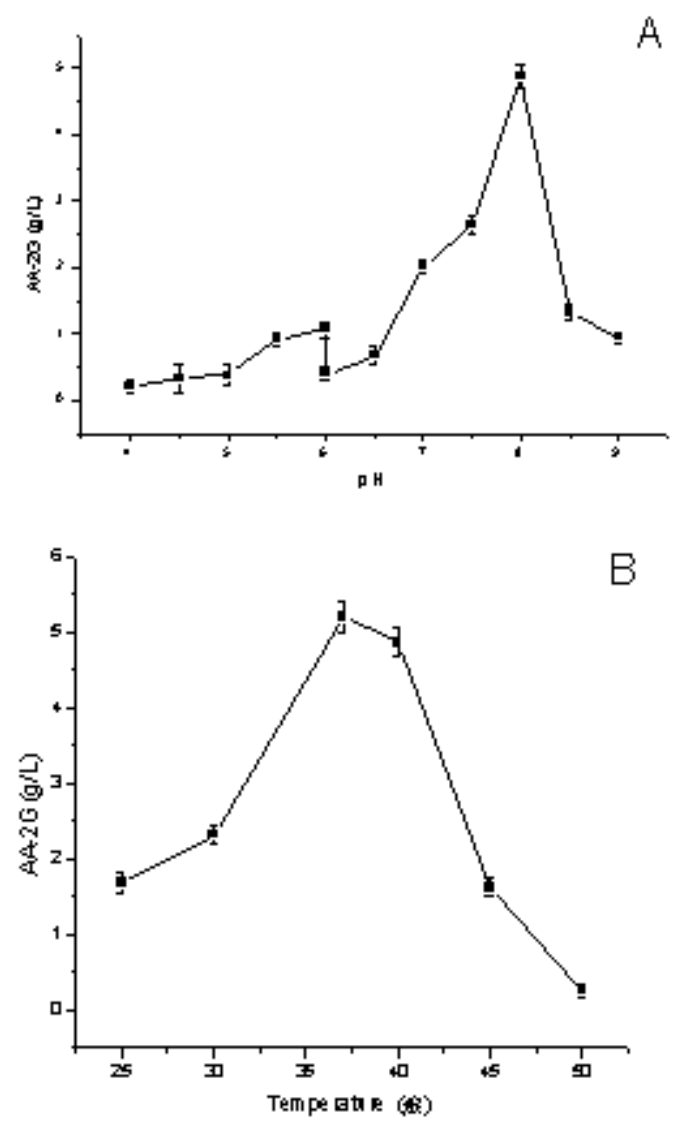

Figure 3. Effect of reaction $\mathrm{pH}(\mathrm{A})$ and temperature (B) on biosynthesis of AA-2G by CGTase from Bacillus sp. SK13.002 with AA $(0.016 \mathrm{~g} / \mathrm{mL})$ and maltose $(0.016 \mathrm{~g} / \mathrm{mL})$ for $24 \mathrm{~h}$.

\subsubsection{Influence of Time and Substrate Ratio on Production of AA-2G}

Figure 4 A shows the time course profile of AA-2G synthesis by CGTase from Bacillus sp. SK13.002 in pH 8.0 at $37^{\circ} \mathrm{C}$. From the initial state $(3 \mathrm{~h}), \mathrm{AA}-2 \mathrm{G}$ production was exponentially increased with time till reached the maximum at $24 \mathrm{~h}$ and stayed constant till $30 \mathrm{~h}$. Other wild and mutant CGTase showed same results [18]. The effects of substrate mass ratio (maltose/AA) on AA$2 \mathrm{G}$ biosynthesis were shown in Figure $4 \mathrm{~B}$, maximum AA-2G production by CGTase from Bacillus sp. SK 13.002 was obtained at a $1: 1$ maltose $(0.016 \mathrm{~g} / \mathrm{L})$ to AA 
$(0.016 \mathrm{~g} / \mathrm{L})$ mass ratio. This result is in agreement with results obtained by other CGTases $[17,19]$.
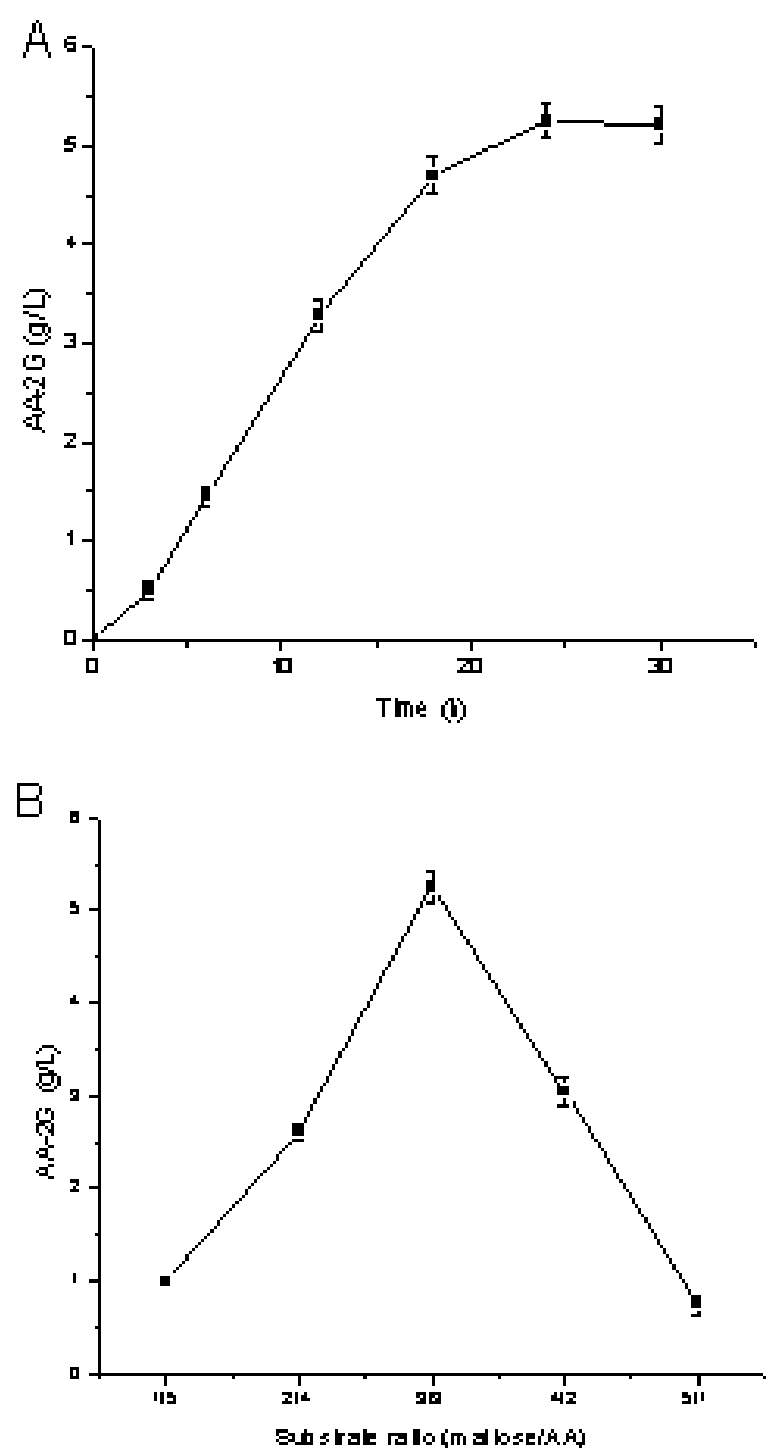

Figure 4. Influence of reaction time (A) and substrate ratios (B) on biosynthesis of AA-2G by CGTase from Bacillus sp. SK13.002 with AA and maltose in $\mathrm{pH} 8.0$ incubated at $37^{\circ} \mathrm{C}$.

\subsubsection{Influence of Enzyme concentration}

The effect of concentration of CGTase from Bacillus sp. SK 13.002 on synthesis of AA-2G is shown in Figure 5. The results show that, maximum AA-2G production is reached when the enzyme concentration is $200 \mathrm{U} / \mathrm{mL}$. Further increase in enzyme concentration after $200 \mathrm{U} / \mathrm{mL}$ showed decrease in AA-2G yield. Decrease of yield after reaching maximum was observed in production of AA-2G by $\alpha$-CGTase from recombinant Escherichia coli, which has maximum AA-2G production at enzyme concentration of $160 \mathrm{U} / \mathrm{mL}$ [17]. These results may indicate that some CGTases may exert hydrolyzing effect on formed AA-2G, but this need to be confirmed. On the other hand, CGTase from Bacillus stearothermophilus hardly was hydrolyzed AA-2G compared to rat and rice $\alpha$-glucosidases [23].

At maximum enzyme concentration the AA-2G yield by CGTase from Bacillus sp. SK13.002 using maltose as a glycosyl donor was $5.5 \mathrm{~g} / \mathrm{L}$. Recombinant CGTase showed maximum AA-2G production $(13 \mathrm{~g} / \mathrm{L})$ using $\beta$ cyclodextrin as a glycosyl donor [17] and CGTase from
Paenibacillus sp. approximately showed a yield of $3 \mathrm{~g} / \mathrm{L}$ AA-2G using dextrin as a glycosyl donor [15]. On the other hand, wild and mutant CGTases from Paenibacillus macerans showed a maximum AA-2G production of 0.85 $\mathrm{g} / \mathrm{L}$ and $1.12 \mathrm{~g} / \mathrm{L}$ respectively using maltose as a glycosyl donor [19]. Comparing our result with last results, the production of AA-2G by CGTase from Bacillus sp. SK13.002 was 6.5 and 4.9-fold of that produced by wild and mutant CGTases from Paenibacillus macerans respectively.

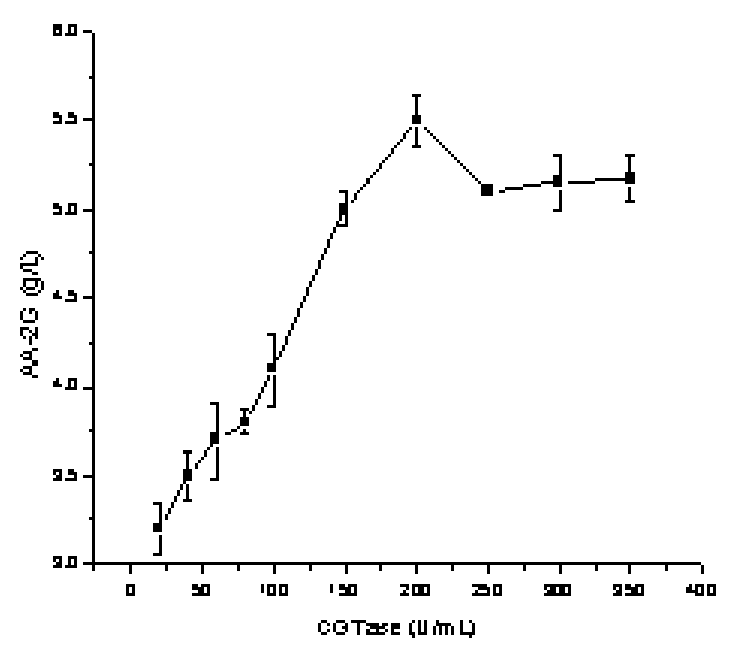

Figure 5. Influence CGTase from Bacillus sp. SK13.002 concentration on biosynthesis of AA-2G from maltose $(0.016 \mathrm{~g} / \mathrm{mL})$ and AA $(0.016$ $\mathrm{g} / \mathrm{mL}$ ) in $\mathrm{pH} 8.0$ incubated at $37^{\circ} \mathrm{C}$ for $24 \mathrm{~h}$.

\section{Conclusions}

The biosynthesis of 2-O- $\alpha$-D-glucopyranosyl-Lascorbic acid (AA-2G) from maltose; the cheap and highly soluble substrate as a glycosyl donor by CGTases was previously reported. However the yield was poor due to low specificity, specificity for maltose was previously improved by site-saturation engineering and the yield increased from 0.85 to $1.12 \mathrm{~g} / \mathrm{L}$. In this study we biosynthesized 2-O- $\alpha$-D-glucopyranosyl-L-ascorbic acid (AA-2G) by CGTase from Bacillus sp. SK 13.002 using ascorbic acid as acceptor and maltose as a glycosyl donor, the results were analyzed by HPLC and confirmed by LC$\mathrm{MS} / \mathrm{MS}$. The AA-2G yield was $1.06 \mathrm{~g} / \mathrm{L}$ in first step, the reaction conditions such as, $\mathrm{pH}$, temperature, time, substrates ratio and enzyme concentration were optimized. At optimum conditions the maximum AA-2G production by CGTase from Bacillus sp. SK 13.002 was $5.5 \mathrm{~g} / \mathrm{L}$. This result indicated that CGTase from Bacillus sp. SK 13.002 is effective in production of AA-2G compared to other CGTases.

\section{Acknowledgement}

This research was financially supported by the National Natural Science Foundation of China (31000764, 20976073, 31230057), the National High Technology Research and Development Program of China (2013AA102102) and the Science \& Technology Pillar Program of Jiangsu Province (BE2013647, BE2012613, BY2012049). 


\section{Statement of Competing Interests}

The authors have no competing interests.

\section{References}

[1] Cruz-Rus, E., Amaya, I. and Valpuesta, V. "The challenge of increasing vitamin C content in plant foods”, Biotechnol J, 7 (9). 1110-1121. 2012

[2] Phillips, K.M., Tarrago-Trani, M.T., Gebhardt, S.E., Exler, J., Patterson, K.Y., Haytowitz, D.B. and Pehrsson, P.R. "Holden, Joanne $\mathrm{M}$ "Stability of vitamin $C$ in frozen raw fruit and vegetable homogenates”, J Food Comp Anal, 23 (3). 253-259. 2010.

[3] Yamamoto, I., Muto, N., Murakami, K. and Akiyama, J. "Collagen synthesis in human skin fibroblasts is stimulated by a stable form of ascorbate, 2-O- $\alpha$-D-glucopyranosyl-L-ascorbic acid”, J Nutr, 122. 871-877. 1992.

[4] Yamamoto, I., Muto, N. Murakami, K., Suga, S. and Yamaguchi, $H$. "L-Ascorbic acid $\alpha$-glucoside formed by regioselective transglucosylation with rat intestinal and rice seed $\alpha$-glucosidases: Its improved stability and structure determination”, Chem Pharm Bull, 38. 3020-3023. 1990.

[5] Yamamoto, I. and Tai, A. "The current state on development of novel vitamin derivatives”, Nippon Rinsho, 57. 2332-2338. 1997.

[6] Mima, H., Nomura, H., Imai, Y. and Takashima, H. "Chemistry and application of ascorbic acid phosphate", Vitamin, 41. 387 1970.

[7] Mead, C.G. and Finamore, F.J. "Occurrence of ascorbic acid sulfate in the brine shrimp, Artemia salina”, Biochem, 8 (6). 2652 2655. 1969

[8] Lu, P.W., Lillard, D.W., Seib, P.A., Kramer, K.J. and Liang, Y.T. "Synthesis of the 2-methyl ether of L-ascorbic-acid - stability, vitamin activity, and C-13 nuclear magnetic-resonance spectrum compared to those of the 1-methyl and 3-methyl ethers”, J Agric Food Chem, 32. 21-28. 1984.

[9] Gregory III, J.F. "Nutritional Properties and Significance of Vitamin Glycosides”, Annu Rev Nutr, 18. 277-96. 1998.

[10] Han, R., Liu, L., Li, J., Du, G. and Chen, J. "Functions, applications and production of 2-O-D-glucopyranosyl-l-ascorbic acid”, Appl Microbiol Biotechnol, 95 (2). 313-320. 2012.

[11] Yamamoto, I., Muto, N., Nagata, E., Nakamura, T. and Suzuki, Y. "Formation of a stable L-ascorbic acid $\alpha$-glucoside by mammalian $\alpha$-glucosidase-catalyzed transglucosylation”, Biochim Biophys Acta, 1035. 44-50. 1990.

[12] Nakamura, S. and Oku, T. "Bioavailability of 2-O- $\alpha$-Dglucopyranosyl-L-ascorbic acid as ascorbic acid in healthy human”, Nutr,. 25. 686-691. 2009
[13] Markosyan, A.A., Abelyan, L.A., Adamyan, M.O., Akopyan, Z.I. and Abelyan, V.A. "Transglycosylation of L-Ascorbic Acid", Appl Biochem Biotechnol, 43 (1). 36-40. 2007.

[14] Lee, S.B., Nam, K., Lee, S.J., Lee, J.H., Inouye, K. and Park, K.H. "Antioxidative effects of glycosyl-ascorbic acids synthesized by maltogenic amylase to reduce lipid oxidation and volatiles production in cooked chicken meat”, Bioscsi Biotechnol Biochem, 68. 36-43. 2004.

[15] Jun, HK., Bae, KM. and Kim, SK. "Production of 2-O- $\alpha-\mathrm{D}$ glucopyranosyl L-ascorbic acid using cyclodextrin glucanotransferase from Paenibacillus sp.”, Biotechnol Lett, 23. 1793-1797. 2001.

[16] Prousoontorn, M.H. and Pantatan, S. "Production of 2-O- $\alpha$ glucopyranosyl L-ascorbic acid from ascorbic acid and bcyclodextrin using immobilized cyclodextrin glycosyltransferase”, J Incl Phenom Macrocycl Chem, 57. 39-46. 2007.

[17] Zhang, Z., Li, J., Liu, L., Sun, J., Hua, Z., Du, G. and Chen, J. "Enzymatic Transformation of 2-O- $\alpha$-D-glucopyranosyl-Lascorbic Acid by $\alpha$-cyclodextrin Glucanotransferase from Recombinant Escherichia coli”, Biotechnol Bioprocess Eng, 16. 107-113. 2011.

[18] Liu, L., Xu, Q., Han, R., Shin, H., Chen, R., Li, J., Du, G. and Chen, J. "Improving maltodextrin specificity for enzymatic synthesis of 2-O-D-glucopyranosyl-L-ascorbic acid by sitesaturation engineering of subsite-3 in cyclodextrin glycosyltransferase from Paenibacillus macerans”, J Biotechnol, 166. 198-205. 2013

[19] Liu, L., Han, R., Shin, H., Li, J., Du, G. and Chen, J. "Biosynthesis of 2-O-D-glucopyranosyl-L-ascorbic acid from maltose by an engineered cyclodextrin glycosyltransferase from Paenibacillus macerans”, Carbohydr Res, 382. 101-107. 2013.

[20] Sun, T., Jiang, B. and Pan, B.L. "Purification and Characterization of Novel Cyclodextrin Glucanotransferase from Bacillus sp SK 13.002”, Asian J Chem, 23 (11). 4977-4982. 2011.

[21] Kwon T., Kim, C.T. and Lee J-H. "Transglucosylation of ascorbic acid to ascorbic acid 2-glucoside by a recombinant sucrose phosphorylase from Bifidobacterium longum”, Biotechnol Lett, 29. 611-5. 2007.

[22] Zhang, Z., Li, J., Liu, L., Sun, J., Hua, Z., Du, G. and Chen, J. "Enzymatic transformation of 2-O- $\alpha$-D-glucopyranosyl-L-ascorbic acid (AA-2G) by immobilized $\alpha$-cyclodextrin glucanotransferase from recombinant Escherichia coli", J Mol Catal B: Enzym, 68. 223-229. 2011.

[23] Tanaka, M., Muto, N. and Yamamoto, I. "Characterization of Bacillus stearothermophilus cyclodextrin glucanotransferase in ascorbic acid 2-O- $\alpha$-glucoside formation”, Biochim Biophys Acta, 1078. 127-132. 1991. 